\title{
Erratum to: Numerical Solution of Riemann-Hilbert Problems: Painlevé II
}

\section{Sheehan Olver}

Published online: 12 February 2011

(C) SFoCM 2011

\section{Erratum to: Found Comput Math \\ DOI 10.1007/s10208-010-9079-8}

This article did not contain the received/revised/accepted dates upon online publication. They are:

Received: 12/23/2009; Revised: 8/6/10; Accepted: 9/9/10

We regret the error.

The online version of the original article can be found under doi:10.1007/s10208-010-9079-8.

S. Olver $(\bowtie)$

Oxford University Mathematical Institute, 24-29 St Giles', Oxford, UK

e-mail: Sheehan.Olver@sjc.ox.ac.uk 